\title{
Notas sobre la evolución del protocolo y el ceremonial en España
}

\section{Notes on the evolution of the protocol and ceremonial in Spain}

Dolores del Mar Sánchez González ${ }^{1}$

UNED

mdmsanchez@der.uned.es

Recepción: 01/07/2015 Revisión:07/09/2015 Aceptación: 09/07/2015 Publicación: 10/07/2015 http:// (página web de inclusión del artículo)

\section{Resumen}

Breves notas sobre la evolución del ceremonial y del protocolo en España desde la Edad Moderna hasta la actualidad.

Palabras clave: Ceremonial, protocolo, simbología del poder, imagen pública.

\section{Abstract}

Brief notes on the evolution of Spanish ceremonial and protocol from the Modern Age to the present day.

Keywords: ceremonial, protocol, symbolism of power, public image.

\section{Sumario}

1. Introducción

2. Desarrollo

3. Conclusiones

4. Bibliografía

\footnotetext{
${ }^{1}$ Profesora Titular, Catedrática acreditada, Académica c. de la RAJL. Coordinadora Master Universitario en Protocolo UNED. Presidenta de la Sociedad de Estudios Institucionales (Seeii). IP GIHPJ-P consolidado de la UNED.
} 


\section{Summary}

1. Introduction

2. Exposition

3. Conclusion

4. Bibliography

\section{INTRODUCCIÓN}

Tengo el convencimiento de que la mejor forma de construir la ciencia del protocolo es desde la Historia de la ciencia del ceremonial y del protocolo. Procedo de una disciplina jurídica, la Historia del Derecho, cuyos orígenes datan de mediados del siglo XIX, caracterizada por una trayectoria muy reciente. La Historia del Ceremonial y del Protocolo es una variante de la Historia Institucional y es precisamente la Historia de la Administración en España la que nos irá diciendo cómo han ido evolucionando el Ceremonial y el Protocolo hasta nuestros días. En este artículo, nos centraremos en la Historia del ceremonial, desde la Edad Moderna hasta la Edad Contemporánea.

La palabra protocolo es polisémica y a menudo se confunde con etiqueta y con ceremonial. Una cosa son los usos sociales y otra las normas jurídicas, y el protocolo es un conjunto de normas. De acuerdo con el DRAE, protocolo es Regla ceremonial diplomática o palatina establecida por decreto o por costumbre. "Regla" significa norma; "ceremonial" alude a determinados actos; "diplomática" se refiere a las relaciones internacionales mostrando esta dimensión internacional; "palatina" nos habla del Estado; "decreto" es un tipo de norma jurídica, y "costumbre" una de las fuentes del Derecho. Por lo tanto, en sentido estricto, sólo es protocolo el Protocolo oficial o Protocolo institucional, considerado como conjunto de normas, usos y costumbres que determinan el orden de celebración de un acto con carácter oficial y las circunstancias que rodean al mismo. Por eso indico siempre que el protocolo no se salta ni se rompe; se cumple o no se cumple.

EI DRAE define el ceremonial como Serie o conjunto de formalidades para cualquier acto público o solemne. Es importante recordar que en el ámbito iberoamericano se usa 
"ceremonial" para referirse a "protocolo". Para nosotros el ceremonial es el procedimiento, el conjunto de pasos que se van siguiendo en un determinado acto de carácter público.

La etiqueta (del francés ètiquette), siguiendo con el DRAE, en su primera acepción designa al Ceremonial de los estilos, usos y costumbres que se debe guardar en las casas reales y en actos públicos solemnes, y, en su segunda, a la ceremonia en la manera de tratarse las personas particulares o en actos de la vida privada a diferencia de los usos de confianza o familiaridad. En la actualidad alude al grado de ceremonialidad manifestado al tratar a otras personas $\mathrm{y}$, sobre todo, al dress code o vestimenta adecuada para un determinado acto o evento. Históricamente, la palabra Etiqueta (colección de usos que en la Casa de Austria y en los inicios de la de Borbón debían cumplir los criados y otras personas recibidas en palacio en la celebración de los actos) expresaba lo que hoy conocemos como protocolo, concepto que prácticamente no aparece (y si lo hace es con un significado distinto) en los textos hasta finales del siglo XIX. Hoy la etiqueta es algo completamente diferente de lo que era en la Edad Moderna.

Los usos sociales, muy relacionados con el protocolo, son normas sin sanción que estructuran la acción humana y la convivencia social en los aspectos no reglados por los ordenamientos jurídicos, políticos o morales. Ciertas costumbres o rituales tienen una difícil clasificación dentro del mundo del protocolo y la etiqueta; incluso algunos pueden ser poco conocidos o estar a punto de desaparecer. Hay ciertas costumbres admitidas por determinadas sociedades que tienen la sancionabilidad del rechazo o la aceptación social. Cada estructura social impone ciertas normas de comportamiento o usos sociales, no jurídicos, que son aceptadas por los demás miembros de la comunidad, y tienen que ver con sus tradiciones y culturas.

\section{DESARROLLO}

El actual protocolo español tiene su origen en Borgoña. El llamado protocolo borgoñón (la Etiqueta Borgoñona propiamente dicha) surge con Felipe III el Bueno, duque de Borgoña, un territorio con proyección en el resto de los territorios europeos y cuyo engarce hace que Felipe III utilice una especial forma de tratamiento, una especial vestimenta y un determinado agasajo como medio para inculcar a sus enemigos políticos la necesidad de 
firmar tratados con él. Crea la Orden del Toisón de Oro para agasajar a determinadas figuras políticas e ir ganando adeptos. En realidad, este protocolo borgoñón es una estrategia política.

La etiqueta borgoñona llegará a España en la época de los Reyes Católicos, pero no son ellos los que la traen sino Felipe el Hermoso, descendiente de Felipe III el Bueno, y su enlace con Juana la Loca. En la ceremonia de consolidación de Juana la Loca y Felipe el Hermoso, como Príncipes de Asturias, agasajará a sus suegros con un banquete borgoñón que impresionará positivamente a los Reyes, por lo ruidoso y festivo, tan diferente del uso castellano de las Coronas de Castilla y Aragón.

Los Reyes Católicos, en sus apariciones públicas, tienen la necesidad de legitimar su poder. La reina accede al poder tras una guerra civil y necesita de la propaganda realizada a través de las ceremonias borgoñonas, todas con la intención de exaltar la realeza y consolidar la monarquía dual. Aunque los cronistas no nos dan una idea precisa de tal ceremonial, sí existen referencias de aquellas ceremonias legitimadoras del poder. Fernando, sobre todo en Castilla, procuró dar mucho más realce a su esposa y así lo hizo en numerosas ocasiones. Tal es el caso de la entrada a Toledo en 1477, precedida por una fuerte discusión entre los esposos sobre el lugar que debía ocupar la reina, reacia a situarse a la derecha mientras él insistía en que ella era la reina de Castilla y, por lo tanto, a ella correspondía ese puesto. Esto nos muestra el enorme valor simbólico de la derecha. Tan es así, que finalmente la reina entrará a la derecha sobre un caballo blanco. Vemos ya que el protocolo legitima y transmite la imagen del monarca, sus atributos y su posición. En Castilla se produce un fenómeno que no se va a repetir hasta siglos después: la reina es rey y el rey su servidor. Siglos después eso será lo que genere un cambio en el protocolo.

A partir de entonces se apreciará la necesidad de adaptación, de cambio, sobre todo cuando llega a la península Carlos V de Alemania y I de España. Recordemos que el emperador creció en Flandes y fue criado a la manera borgoñona. Cuando regresa a España lo hará como un extranjero, desconociendo la lengua y extrañándose ante todo -vestimenta, ceremonias- lo que ve. Los movimientos revolucionarios y la necesidad de hacerse cargo del trono imperial, suponen su pronta marcha dejando a su hijo Felipe II a cargo del gobierno. 
El 15 de agosto de 1545, día de la Asunción de la Virgen, se tiene se empezó a servir al príncipe de España, nuestro Señor, a la manera de Borgoña, por orden del Duque de Alba que Su Majestad Carlos I envió de Alemania para informar a Su Alteza y decidir con Ella el protocolo a observar en su casa, para acompañarle durante el viaje. (Relación del Camino y buen viaje que realizó Felipe II). Esto implica dos modificaciones: un cambio muy importante en la configuración de la Casa real, que pasará de ser la Casa de Castilla a la Casa de Borgoña; y, por otro lado, un cambio importante en la etiqueta, al introducir la etiqueta borgoñona precisamente en el viaje antes aludido.

Así comienza la difusión por Europa de la Etiqueta española, gracias al esplendor de la propia monarquía y a la extensión del Imperio, también a territorios de ultramar, suponiendo la unificación del simbolismo de esa monarquía, que va a utilizar esa etiqueta para consolidar una determinada imagen. Aquí ya se unen el protocolo y el ceremonial con la imagen del poder. Las primeras Etiquetas (Etiquetas generales) son de 1545 . Son descriptivas y no recogen todas las normas de protocolo sino que se limitan a describir cuáles eran las diferentes ceremonias, con sus ceremoniales y precedencias propios, en un momento o en otro. Sufren retoques en 1562 y 1579. La primera adaptación real para adecuarlas al ceremonial será en 1585 con posteriores reformas en 1617, 1624, 1626 y entre 1647 y 1650.

El siglo XVIII supone la llegada de los Borbones. Felipe V viene acostumbrado a la corte del Rey Sol, a Versalles. El "misterioso" incendio del antiguo Alcázar de los Austrias es la circunstancia que aprovecha el nuevo monarca para construir el Palacio Real, a la usanza francesa. Sin embargo, el rey traía instrucciones precisas en cuanto a no hacer más cambios que los estrictamente necesarios, con lo que Felipe $\mathrm{V}$ mantendrá las Etiquetas existentes, que se irán reformando a lo largo del siglo XVIII. Se regularán específicamente las entradas de los embajadores, las ceremonias de recepción de cartas credenciales y es en esta época cuando aparece la figura del Introductor de Embajadores. El elemento característico del siglo XVIII es la continuidad. El ceremonial se convierte, por una parte, en garante de la inviolabilidad del monarca al colocarle en un plano superior e intangible $y$, por otra, en medida de seguridad, para que nadie pueda atentar contra él, dada su inaccesibilidad. Por 
último, el protocolo se configura como un elemento de moralidad para la corte, basada en el establecimiento de las pautas de comportamiento ante los reyes.

Dos momentos marcan el paso entre la etiqueta del Antiguo Régimen al ceremonial moderno. En Europa será la coronación de Napoleón Bonaparte y en España las Cortes de Cádiz.

Las Cortes de Cádiz son la primera institución con un ceremonial propio distinto del ceremonial de la corte. Hasta ahora hemos visto que el ceremonial era algo específico del monarca, del ambiente de la corte, para dar simbolismo a la figura del rey y escenificar su poder. Las Cortes de Cádiz necesitan una legitimidad y para ello asumirán, copiarán, esa proyección del ceremonial que hacía el monarca garantizándose así la aceptación del pueblo. El ceremonial se convierte en el elemento legitimador. Con esa regulación específica, que llega a intitularlas "Majestad" en el segundo de los decretos, surge el ceremonial de Estado, parlamentario y diferenciado del de la corte, para las instituciones políticas. El protocolo es la forma en que las instituciones transmiten una determinada imagen a la sociedad.

José Napoleón I, todavía hoy considerado como el "rey intruso", hace una reestructuración en las Etiquetas respecto de la Casa real a partir de todo lo aprendido de su hermano Napoleón Bonaparte. Distribuye el Palacio Real en siete salas, concebidas como círculos distintos en torno a la figura del monarca, con sus propias precedencias en cada una de ellas. Al primer círculo, íntimo, sólo acceden las personas más allegadas al monarca, con funciones tales como despertarle, levantarle o vestirle, entre las que hay una prelación, un orden de precedencias. En el segundo círculo, hay otras personas, con sus propias precedencias, que no pueden acceder al primero. Así sucesivamente, hasta completar los siete. Aparece la figura del maestro de ceremonias, como uno de los jefes de palacio.

Con la restauración del Antiguo Régimen y los Borbones, esta etiqueta desaparece. Fernando VII restaura las tradicionales etiquetas de la Casa de Austria y Borbón y se atisba una ligera adaptación del el ceremonia a la modernidad. Lo más característico son las llamadas Entradas Reales, las ceremonias con las que se transmitía al pueblo que el rey, o su esposa, o la Princesa de Asturias ese momento de llegada a la ciudad. 
El segundo momento más determinante en la evolución del protocolo, tras las Cortes de Cádiz, se encuentra en la regencia de María Cristina y los inicios del reinado de Isabel II. AI morir Fernando VII, la reina no ostenta la mayoría de edad, por lo que será su madre la encargada de asumir la regencia. María Cristina reelabora las antiguas etiquetas para adaptarlas al hecho de que la reina ahora es rey: al primer círculo, lógicamente, sólo accederán mujeres; las salas quedan reducidas a cinco, cada una con sus precedencias, y se abre el acceso a palacio a las mujeres no ya sólo por ser cónyuges de oficiales con cargo en la corte, sino porque tengan allí sus oficios.

Tenemos en este momento dos acontecimientos importantes. Por un lado, María Cristina tiene que pactar con los liberales, durante las guerras carlistas por la cuestión dinástica, y fruto de ese pacto surge una nueva situación política. Por otro, por primera vez se va a dar entrada a palacio de los diputados de Cortes, algo realmente importante por cuanto supone que tales autoridades tendrán proyección en el mundo de palacio, aunque sea ceremonial de corte. Esto supone que las instituciones tendrán una mayor visibilidad.

Ya en el reinado de Isabel II, la etiqueta se consolida en 1840 con, al menos, cien ceremonias descritas en lo que podríamos considerar un cuaderno de ceremonias. Se considera que la primera norma específica de protocolo es el Real Decreto de 17 de mayo de 1856 Aclarando y determinando el lugar que le corresponde a las Autoridades y Corporaciones en los actos públicos y en el acto de recibir a la Corte, estableciendo por primera vez el protocolo para alguien que no sea un rey, caso de los gobernadores civiles que, en los actos públicos civiles, tienen una reglamentación especial consistente en un besamanos. Las mismas ceremonias de besamanos que existían en las Cortes se trasladan a las provincias, donde los gobernadores civiles iniciarán las líneas de saludos. Es decir, ya tenemos autoridades civiles imitando el comportamiento de la Casa real.

El ceremonial de palacio sigue siendo el más importante. Con Alfonso XIII, tenemos la Orden Real de 1908, de 15 de enero, denominada Orden que para la entrada en el Salón del Trono y Desfile ante su Majestad debe regir en todas las recepciones generales, recuperando la etiqueta de José I y sus siete categorías de precedencias. Cabe destacar la importancia de la influencia inglesa recibida a través de Victoria Eugenia de Battembreg. 
La dictadura del General Franco, aunque durante bastante tiempo siguió utilizando la Etiqueta de los Borbones, impone el Reglamento de 27 de junio de 1968, de Precedencias y Ordenación de Autoridades y Corporaciones. Por primera vez clasifica los actos, clasifica las autoridades y establece unos determinados ámbitos de aplicación, respecto de actos oficiales y cargos públicos. Lo más importante es que el actual RD de Precedencias es una copia de este Decreto, tan literal que comete muchos de los mismos errores.

\section{CONCLUSIÓN}

Para finalizar, quiero poner de manifiesto el cambio muy importante que se produce desde el ceremonial y el protocolo como medios para consagrar la imagen del monarca, hasta el protocolo como forma de consagrar la imagen del poder, que es específicamente lo que va a ocurrir a lo largo del siglo XIX. Ya en el siglo XX, ese protocolo va a ser utilizado por las empresas, corporaciones y otras instituciones.

\section{BIBLIOGRAFÍA}

BARRIOS, F. (2002), "Solórzano, la Monarquía y um conflito entre Consejos", em Derecho y Administración pública em las Indias hispânicas, I, Universidad Castilla-La Mancha, págs. 265284.

CARRASCO MANCHADO, A.I. (2006), "Isabel la Católica y las ceremonias de la Monarquía", eSpania, jun. 2006. DOI 01/05/2015 en http://e-spania.revues.org/308?lang=it

DOMINGUEZ ADAME, M. (2001), "Reflexiones sobre el protocolo municipal en los comienzos del s. XXI", Laurea, 1, págs. 57 y ss.

KERTZER, D.I. (1998), Rituals, politis, and power, Yale University Press.

MARTÍNEZ PEÑAS, L. (2013), "El informe de Fernando Carrillo sobre conflictos de precedência", Revista Aequitas: Estudios sobre historia, derecho e instituciones, №. 3, págs. 189-220.

NÖEL, CH. C. (2004), "La etiqueta borgoñona en la Corte de España (1547-1800)", Manuscrits, 22, págs, 139-158.

OTERO, M. T. (2004), "Relaciones públicas, ceremonial y protocolo", en Las relaciones públicas en España / coord. por José Luis Arceo Vacas, págs. 277-288.

OTERO, M. T. (2001), “Ceremonial y protocolo”, Laurea, 1, págs. 9-21. 
SÁNCHEZ GONZÁLEZ, D.del M. (2011), Fundamentos del ceremonial y del protocolo, Madrid, Síntesis.

SÁNCHEZ GONZÁLEZ, D. del M. (2012), "Cuestiones de ceremonial y protocolo en las Cortes de Cádiz", en ALVARADO, M.T. (coord.), Actas del XIII Congreso Internacional de Protocolo, OICP_EIP, pp. 266-282.

SÁNCHEZ GONZÁLEZ, D. del M. (2013), "Análisis comparativo de la normativa sobre protocolo en las Universidades españolas", Revista Internacional de Relaciones Públicas, vol 3, no 5 (enero-junio), DOI 01/05/2015 em

http://revistarelacionespublicas.uma.es/index.php/revrrpp/article/view/167

SÁNCHEZ GONZÁLEZ, D. del M. (2014), "Protocolo y Derecho: la juridicidad del protocolo", en Actas del I Congreso Internacional "El Protocolo contemporáneo: desde el Congreso de Viena hasta la actualidad (1814-2014)", DOI 01/05/2015 em

http://www.estudiosinstitucionales.com/4.html 